\title{
Suitability of Mulch and Ridge-furrow Techniques for Maize across the Precipitation Gradient on the Chinese Loess Plateau
}

\author{
Jiansheng $\mathrm{Ye}^{1} \&$ Changan $\mathrm{Liu}^{2}$ \\ ${ }^{1}$ State Key Laboratory of Pastoral Agricultural Ecosystem, Institute of Arid Agroecology, School of Life \\ Sciences, Lanzhou University, Lanzhou, China \\ ${ }^{2}$ Cold and Arid Regions Environmental and Engineering Research Institute, Chinese Academy of Sciences, \\ Lanzhou, China \\ Correspondence: Jiansheng Ye, State Key Laboratory of Pastoral Agricultural Ecosystem, Institute of Arid \\ Agroecology, School of Life Sciences, Lanzhou University. No. 222, South Tianshui Road, Lanzhou 730000, \\ China. Tel: 86-139-1914-5033. E-mail: yejiansheng30@gmail.com
}

Received: June 27, $2012 \quad$ Accepted: July 17, $2012 \quad$ Online Published: August 28, 2012
doi:10.5539/jas.v4n10p182
URL: http://dx.doi.org/10.5539/jas.v4n10p182

\begin{abstract}
Mulch and ridge-furrow are effective techniques to improve water harvest, reduce evaporation and increase crop productivity in dry rainfed areas. We collected grain yield data of maize (Zea mays L.) across the precipitation gradient on the Loess Plateau under three treatments: (1) CK, flat plot without mulch; (2) HM, half-mulch flat plot, i.e. alternating mulched row and bare row without ridge-furrow; and (3) DRM, double ridges and the furrow fully mulched with plastic film. Maize grain yields were highest in the DRM treatment and lowest in the CK treatment. Mulch or ridge-furrow with mulch have increased maize grain yield significantly. The highest increase was found in low growing season precipitation regimes. Grain yields of the three treatments trended to converge in high growing season precipitation regimes. Regressions between grain yields and growing season precipitation for the three treatments showed that maize yields increased linearly with precipitation for CK; statistically significant quadratic models were found for HM and DRM treatments. The economic net incomes were calculated based on yields and inputs of capital and labor for the three treatments. Considering both water resource and economic outcome, we recommend that a precipitation range of $196-532 \mathrm{~mm}$ is most suitable for mulch and ridge-furrow techniques for maize on the Loess Plateau. Spatially, CK and HM treatment were most suitable for small parts of the southeast part of the plateau and DRM was suitable for most of (87\%) the plateau.
\end{abstract}

Keywords: precipitation, maize, plastic film mulch, ridge, furrow

\section{Introduction}

Agricultural productivity in semi-arid area is highly dependent on water availability ( $\mathrm{Li}$ et al., 1999; Ye et al., 2010; Zhao, 1996). The Loess Plateau in northwest of China (Figure 1), covering an areas of $640,000 \mathrm{~km}^{2}$ or about $6.7 \%$ of the total land area of China (Zhang \& Liu, 2010), is mainly characterized by a semiarid monsoon climate (also includes a small part of arid and sub-humid areas). Lacking other water resources for irrigation, precipitation is the only water resource for agriculture production. Low and variable precipitation combined with high evaporation (annual free water evaporation can be three times higher than annual precipitation) often lead to low crop yields on the Loess Plateau (Li et al., 2001; Liu et al., 2009; Wang et al., 2004). Therefore, rainwater harvesting and soil moisture conservation play an important role in agricultural production (Li et al., 1999; Liu et al., 2009; Zhao, 1996).

Mulches have long been used in agriculture to reduce water loss through evaporation, (Li et al., 1999). The technique has been successfully applied to a number of crops including wheat (Triticum aestivum) (Chakraborty et al., 2008; Li et al., 1999) and maize (Zea mays L.) (Wang et al., 2011a; Zhou et al., 2012). Straw is an effective mulch material (Langdale et al., 1992), but the application of straw mulch is restricted on the Loess Plateau because grain yield may be decreased due to lower soil surface temperature (Gao \& Zhao, 1995). To address this problem, plastic (polyethylene) film mulch was introduced to China in 1978, and the technique has since been adopted widely (Luo, 1982). The conventional plastic film mulch technique for maize is called "half-mulch flat-plot (HM)" i.e. alternating plastic film mulched row and bare row without ridge (Liu et al., 1989). Ridge and furrow have been developed to harvest rainwater after that, and a new mulching pattern-double 
ridges and the furrow fully mulched with plastic film (DRM)-has been developed for maize since 2007 and achieved a significant improvement in grain and forage production (Zhou et al., 2012). The new planting and mulching pattern has been wieldy adopted. For example, land area using this pattern reached $1.93 \times 10^{5}$ ha in Gansu Province in northwest of China during 2008, which occupied about 7\% of the total cropland and contributed $20 \%$ to the total grain production (Wang, 2009) (http://www.gs.xinhuanet.com/news/2009-01/17/content_15482691.htm, access 8 June 2012). In 2012, this pattern is expected to be adopted over $1 \times 10^{6}$ ha land areas in four major dryland farming provinces (whole Shanxi and Ningxia provinces and a large part of Gansu and Shaanxi provinces belong to the Loess Plateau) in China, the grain yield of maize is expected to be $3.21 \times 10^{5}$ ton (http://xbkf.chinawestnews.net/system/2010/06/25/010283475.shtml, access 8 June 2012).

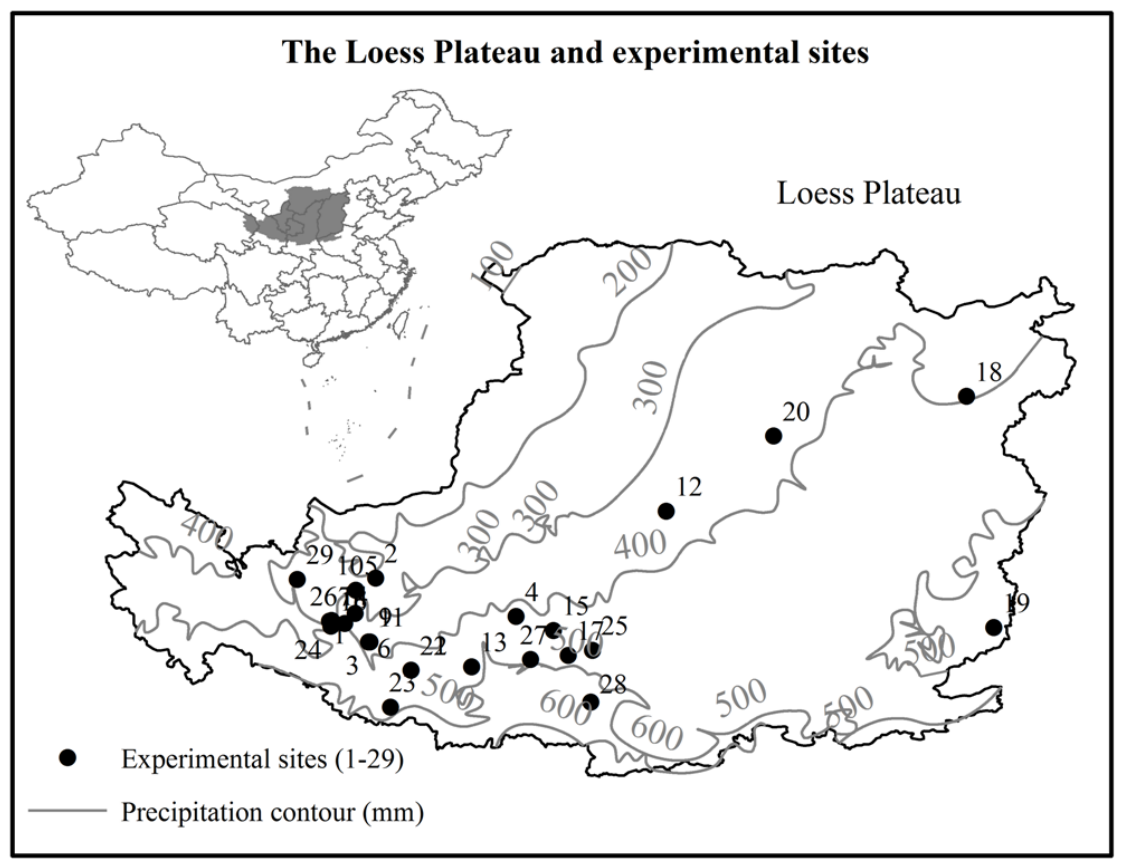

Figure 1. Location of the Loess Plateau in China and the experimental sites considered from literature review

The objectives of this study were to (i) analyze effect of plastic film mulch and ridge-furrow techniques on maize grain yield across the precipitation gradient; (ii) map the spatial distribution of grain yield potential on the Loess Plateau under recent (1950-2000) climate. Agriculture is not only influenced by climate but also by economic and technological factors ( $\mathrm{Li}$ et al., 2011). While plastic film mulch and ridge-furrow techniques can increase grain yield and economic benefit compared to conventional cultivation, it requires significant inputs as capital and labor (Liu et al., 2009). Therefore, it is also meaningful to (iii) delineate potential areas that will benefit from using the techniques or suitable areas for adopting the techniques on the plateau.

\section{Materials and Methods}

\subsection{Site Based Grain Yield and Precipitation Data}

Grain yields of maize with three treatments were compiled across the Loess Plateau through a comprehensive literature review (Figure 1 and Table 1). The three treatments considered were (1) flat-plot sowing without ridge-furrow mulching (CK, Figure 2a), (2) half-mulched flat-plot, i.e. alternating plastic film mulched row and bare row on flat plots (HM, Figure $2 b$ ), (3) double ridges and the furrow fully mulched with plastic film, maize is sown in the furrow (DRM, Figure 2c). Most of the studies provided grain yields and the corresponding growing season (from April to September) precipitation data. For studies only have yield data, we obtained precipitation data from the nearest meteorological station for the same year. Regressions were conducted between grain yields and growing season precipitation. 
Table 1. Experimental sites across the growing season precipitation gradient on the Loess Plateau

\begin{tabular}{|c|c|c|c|}
\hline Experimental sites & Precipitation (mm) & Experimental year & Source $^{\S}$ \\
\hline 1 & 180 & 2004 & 1 \\
\hline 2 & 197 & 2007 & 2 \\
\hline 3 & 197 & 2009 & 3 \\
\hline 4 & 209 & 2008 & 4 \\
\hline 5 & 213 & 2007 & 5 \\
\hline 6 & 229 & 2010 & 6 \\
\hline 7 & 274 & 2009 & 7 \\
\hline 8 & 283 & 2004 & 8 \\
\hline 9 & 284 & 2009 & 9 \\
\hline 10 & 287 & 2006 & 9 \\
\hline 11 & 293 & $2008-2010$ & 9 \\
\hline 12 & 294 & 2010 & 9 \\
\hline 13 & 294 & 2009 & 10 \\
\hline 14 & 308 & $2008-2010$ & 10 \\
\hline 15 & 310 & 2009 & 11 \\
\hline 16 & 314 & 2007-2009 & 12 \\
\hline 17 & 328 & $2007-2009$ & 13 \\
\hline 18 & 333 & 2009 & 13 \\
\hline 19 & 373 & 2009 & 14 \\
\hline 20 & 401 & 2006 & 15 \\
\hline 21 & 406 & 2007 & 13 \\
\hline 22 & 436 & 2005 & 16 \\
\hline 23 & 436 & 2007 & 16 \\
\hline 24 & 447 & 2007 & 16 \\
\hline 25 & 449 & $2008-2010$ & 16 \\
\hline 26 & 455 & 2007 & 16 \\
\hline 27 & 461 & $2008-2010$ & 17 \\
\hline 28 & 462 & 2009 & 17 \\
\hline 29 & 560 & 2007 & 18 \\
\hline
\end{tabular}

$\S 1=$ (Zhang et al., 2005); $2=$ (ATESGS, 2009); $3=$ (Wang et al., 2011b); $4=($ Ma et al., 2011); $5=$ (Zhou et al., 2009); $6=$ (Liu et al., 2008); $7=($ Zhao, 2005); $8=($ Huang et al., 2010a); $9=($ Huang et al., 2010b); $10=($ Hai, 2011); $11=$ (Zhang et al., 2010); $12=$ (Zhang et al., 2011); $13=($ Zhi et al., 2011); $14=($ Yan et al., 2010$) ; 15=$ (Shi et al., 2008); $16=(\mathrm{Ji}, 2006) ; 17=($ Zhen, 2008); $18=($ Wang, 2010) 


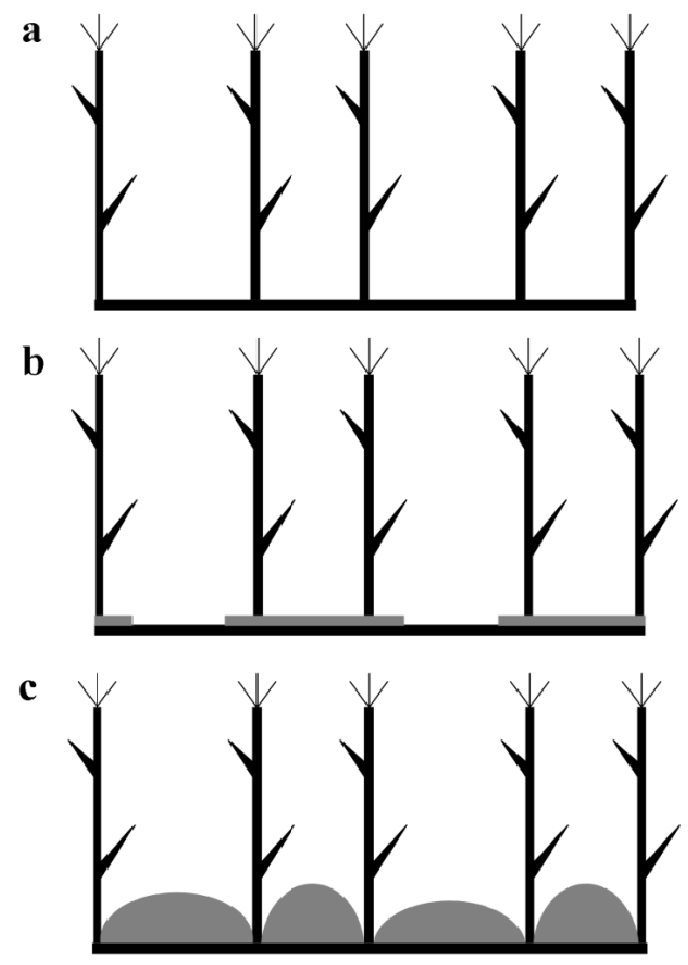

Figure 2. Maize planted using three methods. (a) flat-plot sowing without ridge-furrow mulching (CK), (b) half-mulched flat-plot, i.e. alternating plastic film mulched row and bare row on flat plot (HM), (c) double ridges and the furrow fully mulched with plastic film, maize is sown in the furrow (DRM)

\subsection{Gridded Precipitation Data}

To analyze the spatial distribution of grain yields, growing season precipitation data (average of 1950-2000) were obtained from WorldClim (Hijmans et al., 2005) (available at http://www.worldclim.org/), a publicly available global database of climate surfaces at 30 arc-second spatial resolution $(\sim 1 \mathrm{~km}$ at the Equator). Tuner et al. (2011) compared the data against the observation from the Chinese Meteorological Administration (CMA) in the period from 1980 to 2008 for 10 stations across the Loess Plateau and found good agreement.

\section{Results}

\subsection{Grain Yields across the Precipitation Gradient}

An experimental dataset was collected by comprehensive literature review (Figure 1, Table 1). Maize grain yields were highest in the DRM treatment and lowest in the CK treatment. Mulch or ridge-furrow with mulch have increased maize grain yield significantly (ANOVA test). The highest increase was found in low growing season precipitation regimes. Grain yields of the three treatments trended to converge in high growing season precipitation regimes. Regressions between grain yields and growing season precipitation for the three treatments showed that maize yields increased linearly with precipitation for CK; statistically significant quadratic models were found for HM and DRM treatments (Figure 3).

\subsection{Economic Benefit across a Precipitation Gradient}

It is important to analyze how farmers will benefit from using mulch and ridge-furrow techniques since they need inputs of capital and labor (Table 2). Input was highest in DRM treatment, followed by HM treatment and CK. Maize price was around 0.24 USD kg-1 (1.5 CNY kg-1) during recent years (Liu et al., 2009; Liu et al., 2008).

Based on the yield-growing season precipitation regression models (Figure 3a) and economic inputs (Table 2), the net income across the precipitation gradient were estimated by subtracting inputs from outputs for the three treatments. Farmers will benefit most by using DRM treatment where growing season precipitation is $<532 \mathrm{~mm}$, $\mathrm{HM}$ treatment where growing season precipitation is between 534 and 584, and CK where growing season precipitation is $>584 \mathrm{~mm}$ (Figure $3 \mathrm{~b}$ ). 

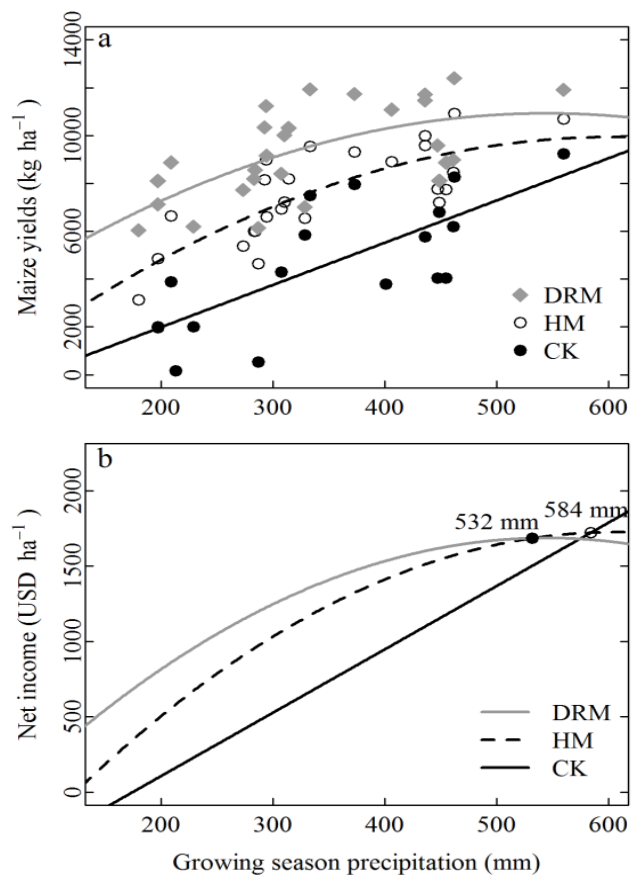

Figure 3. Maize grain yields (a) and net income (b) under the three treatments (see Figure 2 for description of the three treatments) across the growing season precipitation gradient on the Loess Plateau. Regressing grain yield against growing season precipitation, linear model is found for CK $\left(y=18 \mathrm{x}-1538, \mathrm{r}^{2}=0.55, \mathrm{p}<0.001\right)$ and quadratic models are found for HM $\left(y=-0.031 x^{2}+38 x-1494, r^{2}=0.60, p<0.001\right)$ and DRM $\left(y=-0.031 x^{2}+\right.$ $34 x+1793, r^{2}=0.39, p<0.00$ ). In Figure $3 b$, the black dot is the intersection (precipitation is $532 \mathrm{~mm}$ ) of $\mathrm{HM}$ and DRM lines, and the hollow dot is the intersection (precipitation is $584 \mathrm{~mm}$ ) of CK and HM lines

Table 2. Economic inputs (USD ha ${ }^{-1}$ ) of maize in three treatments (see Figure 2 for description of the three treatments) on the Loess Plateau

\begin{tabular}{lrrr}
\hline & CK & HM & DRM \\
\hline Seed & 25.0 & 25.0 & 25.0 \\
Phosphate fertilizer & 47.6 & 47.6 & 47.6 \\
Farmyard manure & 47.6 & 47.6 & 47.6 \\
Nitrogen fertilizer & 152.4 & 152.4 & 152.4 \\
Plastic film & 0.0 & 83.3 & 166.7 \\
Plough & 95.2 & 95.2 & 95.2 \\
Labor cost for mulching and making & 0.0 & 190.5 & 381.0 \\
ridge-furrow & & & \\
\hline Total & 367.9 & 641.7 & 915.5 \\
\hline
\end{tabular}

Notice that net incomes under DRM treatments are still higher than that of CK in low growing season precipitation regimes such as those $<100 \mathrm{~mm}$ (Figure $3 \mathrm{~b}$ ). We assumed that farmers will adopt the mulch and furrow-ridge only if net income is $\geq 790 \mathrm{USD} \mathrm{ha}^{-1}$ (or $5000 \mathrm{CNY} \mathrm{ha}{ }^{-1}$, the average net income per ha farmland on the Loess Plateau), the minimum precipitation needed is about $196 \mathrm{~mm}$. Therefore, the growing season precipitation range suitable for the mulch and ridge-furrow techniques (DRM) is $196-532 \mathrm{~mm}$.

\subsection{Spatial Distribution of Grain Yield Potential}

In recent history (1950-2000), growing season precipitation tended to decrease gradually from southeast to northwest of the Loess Plateau (Figure 1). Based on the regression models and gridded precipitation data, the spatial distributions of grain yield potentials were estimated for the three treatments (Figure 4). Without mulch and ridge-furrow (i.e. CK), grain yields were highest in the south and southeast of the Loess Plateau where precipitation was also highest (Figure 4a). The average grain yield was $5142 \mathrm{~kg} \mathrm{ha}^{-1}$ for the whole plateau. Generally, grain yields under HM treatment were higher $\left(2820 \mathrm{~kg} \mathrm{ha}^{-1}\right.$ in average or about $\left.55 \%\right)$ than those of 
CK, however, negative effects are found in a small part of the south of Loess Plateau where precipitation was the highest (Figure 4b). Spatial distribution of grain yields under DRM treatment was very similar to that under HM treatment (Figure 4c); yields were higher $\left(4569 \mathrm{~kg} \mathrm{ha}^{-1}\right.$ or $89 \%$ ) than those of CK in average.
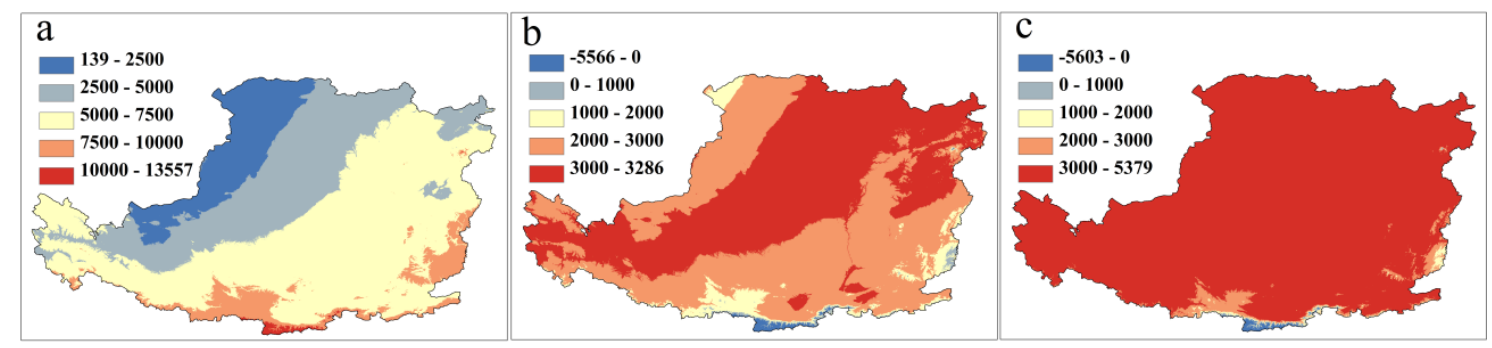

Figure 4. Maize grain yield potentials $\left(\mathrm{kg} \mathrm{ha}^{-1}\right)$ under three treatments (see Figure 2 for description of the three treatments) on the Loess Plateau. (a) Yields of CK treatment; (b) yields difference between HM and CK treatments (HM-CK); (c) yields difference between DRM and CK treatments (DRM-CK)

\subsection{Suitable Areas of Mulch and Ridge-furrow Techniques for Maize}

Spatial distributions of net income potential for the three treatments were estimated. For each grid, the maximum net income was calculated for the three treatments and only grids with net incomes $\geq 790$ USD ha $^{-1}$ were regarded as suitable for maize cultivation. CK and HM treatments were most suitable for small parts of the south and east of the Loess Plateau (Figure 5a-b), they occupied 5\% of the land areas in total. DRM treatment was suitable for most land areas ( $87 \%$ ) of the plateau (Figure $5 \mathrm{c}$ ). $8 \%$ of the land areas were not suitable for maize.

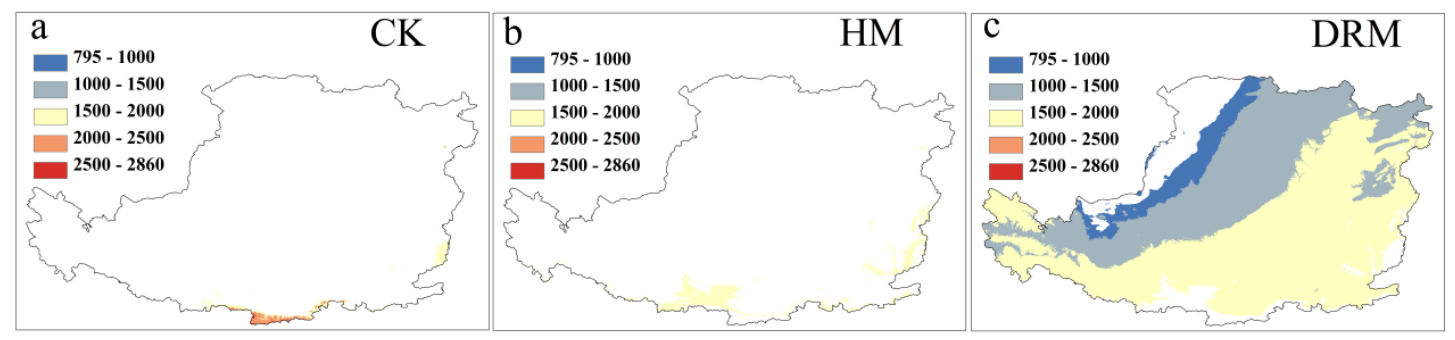

Figure 5. Maximum net income potentials $\left(\mathrm{USD} \mathrm{ha}^{-1}\right.$ ) and the corresponding treatment (see Figure 2 for description of the three treatments) on the Loess Plateau. (a) Areas suitable for CK and the corresponding net income potential; (b) areas suitable for HM and the corresponding net income potential; (c) areas suitable for

DRM and the corresponding net income potential

\section{Discussion}

The mulch and ridge-furrow techniques greatly increased the grain yield of maize, which is mainly due to the effect of plastic film on reducing water evaporation from soil (Li et al., 2004; Liu et al., 2009) and ridge-furrow on increasing rainwater harvesting ( $\mathrm{Li}$ et al., 2001; Wang et al., 2005). Therefore, the techniques reduced the sensitivity of maize yield to change in precipitation. The benefit of mulch and ridge-furrow decreased as precipitation increased. There is less or even no need to reduce evaporation and harvest rainwater because precipitation is enough for crop growth in humid region.

Rainwater harvesting has been an effective technique for improving productivity and thus livelihoods of residents in the vast dryland worldwide (Ngigi, 2003). Generally speaking, rainwater harvesting is suitable for arid and semi-arid region where no irrigation is available or the cost of irrigation is too high (Tian et al., 2003). In regions with annual precipitation ranging from 100 to $700 \mathrm{~mm}$, low cost water harvesting might provide an promising alternative if irrigation water from other sources is not readily available or too costly (Prinz, 1996). Others suggested that areas with precipitation large than $250 \mathrm{~mm}$ is most suitable for rainwater harvesting agriculture on dryland (Boers et al., 1986; Li, 1998). Zhang et al. (2010) suggested that mulch and ridge-furrow techniques were most suitable for regions with annual precipitation between $300 \sim 500 \mathrm{~mm}$. Pacey and Cullis (1986) gave a more conservative range of annual rainfall, 500-600 mm. However, the application potential for 
the mulch and ridge-furrow techniques are not only dependent on climate (especially precipitation) but also on labor and capital factors (Ali and Yazar, 2007; Liu et al., 2009). Based on multiple experimental sites across the precipitation gradient on the Loess Plateau, we recommend that a growing season precipitation range of 196-532 $\mathrm{mm}$ was suitable for mulch and ridge-furrow techniques for maize in this region, considering both water resource and economic outcome. The lower end of the precipitation range is in between $100 \mathrm{~mm}$ suggested by Prinz (1996) and $250 \mathrm{~mm}$ suggested by Boers et al. (1986) and Li (1998), the higher end of range is in between $500 \mathrm{~mm}$ suggested by Zhang et al. (2010) and $600 \mathrm{~mm}$ suggested by Pacey and Cullis (1986). Although this range did not include impact of other environmental factors, it is still useful because farmers are able to easily decide what treatment to use in different precipitation regimes.

Some studies used multi-criteria evaluation or other methods to delineate suitable areas for agriculture or specific crop based on climate, relief and soil factors (Ceballos-Silva \& López-Blanco, 2003; Reshmidevi et al., 2009; Ye et al., 2010). The unique feature of the present study is inclusion of social economic variables to assess the suitability of different techniques across the precipitation gradient. We only considered the economic inputs of materials and labor force for the three techniques in the current study (Table 2). The ecological aspect such as negative effect of plastic residue in soil and the fate of breakdown products are unclear and are recently being measured (Turner et al., 2011; Yan et al., 2006). Four major dryland farming provinces in China plan to allocate more land areas to adopting plastic film much and ridge-furrow techniques in the near future. The results of the study are useful for governments and farmers to decide what land to adopt the techniques in this region and in similar regions of the world.

\section{Conclusions}

In this study, grain yields data of maize in three treatments (CK, HM and DRM) on the Loess Plateau were compiled from comprehensive literature review. Grain yield of maize was highest in DRM treatment and lowest in CK. The difference of grain yields among the three treatments were highest in low growing season precipitation regime, they trended to converge in high growing season precipitation regime. The benefit of mulch and ridge-furrow decreased as precipitation increased. The economic net incomes were calculated based on yields and inputs of capital and labor for the three treatments. Considering both water resource and economic outcome, we recommend that a growing season precipitation range of $196-532 \mathrm{~mm}$ as most suitable for mulch and ridge-furrow techniques for maize on the Loess Plateau. Spatially, CK and HM treatments were most suitable for small parts of the south and east of the plateau where precipitation was highest. DRM treatment was suitable for most land areas (87\%) on the Loess Plateau.

\section{Acknowledgements}

This study is supported by the Fundamental Research Funds for the Central Universities, lzujbky-2012-111 and the Key Project of International Science \& Technology Cooperation: Construction of an Information Platform/module in Eco-agricultural Assessment and Management (EAM), 2010DFA31450.

\section{References}

ATESGS. (2009). Study and demonstration of high precipitation use efficiency with plastic film mulch and double ridge-furrows in dry land. Gansu: Agricultural Technology Extension Station at Gansu Province, China.

Boers, T. M., Zondervan, K., \& Ben-Asher, J. (1986). Micro-Catchment-Water-Harvesting (MCWH) for arid zone development. Agricultural Water Management, 12(1-2), 21-39. http://dx.doi.org/10.1016/0378-3774(86)90003-X.

Ceballos-Silva, A., \& López-Blanco, J. (2003). Delineation of suitable areas for crops using a Multi-Criteria Evaluation approach and land use/cover mapping: a case study in Central Mexico. Agricultural Systems, 77(2), 117-136. http://dx.doi.org/10.1016/S0308-521X(02)00103-8.

Chakraborty, D., Nagarajan, S., Aggarwal, P., Gupta, V. K., Tomar, R. K., Garg, R. N., et al. (2008). Effect of mulching on soil and plant water status, and the growth and yield of wheat (Triticum aestivum L.) in a semi-arid environment. Agricultural Water Management, 95(12), 1323-1334. http://dx.doi.org/10.1016/j.agwat.2008.06.001.

Gao, S., Gao, J., \& Li, C. (2010). Full plastic film mulch and double ridge-furrows technique for maize in dryland of Jingbian. Jilin Agricultural, 11, 143. (in Chinese).

Gao, S., \& Zhao, S. (1995). Research on the compensatoryeffects to waterdeficits on drylandspringwheat in semiaridarea. Acta Botanica Boreali - Occidentalia Sinica, 15(8), 32-39 (in Chinese). 
Hai, L. (2011). Effects of plastic-film mulching on maize yields and soil quality in the semi-arid Loess Plateau of China. Unpublished Doctor, Lanzhou Universtiy, Lanzhou (in Chinese).

Hijmans, R. J., Cameron, S. E., Parra, J. L., Jones, P. G., \& Jarvis, A. (2005). Very high resolution interpolated climate surfaces for global land areas. International Journal of Climatology, 25(15), 1965-1978. http://dx.doi.org/10.1002/joc.1276.

Huang, G., Fang, Y., Li, L., Xie, J., \& Wang, J. (2010). High water use efficiency mechanism of maize planting in furrows of completely mulched alternating narrow and wide ridges systems in rainfed area. Agricultural Research in the Arid Areas, 6, 116-121 (in Chinese).

Ji, C. (2006). Study on full plasitc film mulch and double ridge-furrows cultivation technique for maize on dryland. Gansu Agriculture, 4, 254 (in Chinese).

Langdale, G. W., West, L. T., Bruce, R. R., Miller, W. P., \& Thomas, A. W. (1992). Restoration of eroded soil with conservation tillage. Soil Technology, 5(1), 81-90. http://dx.doi.org/10.1016/0933-3630(92)90009-P.

Li, F. (1998). Studies on Arid Agricultural Ecosystems. Xi'an: Shaanxi Scientific and Technology Publishing House.

Li, F., Guo, A., \& Wei, H. (1999). Effects of clear plastic film mulch on yield of spring wheat. Field Crops Research, 63(1), 79-86. http://dx.doi.org/10.1016/S0378-4290(99)00027-1.

Li, F., Song, Q., Jjemba, P. K., \& Shi, Y. (2004). Dynamics of soil microbial biomass C and soil fertility in cropland mulched with plastic film in a semiarid agro-ecosystem. Soil Biology and Biochemistry, 36(11), 1893-1902. http://dx.doi.org/10.1016/j.soilbio.2004.04.040.

Li, X. Y., Gong, J. D., Gao, Q. Z., \& Li, F. R. (2001). Incorporation of ridge and furrow method of rainfall harvesting with mulching for crop production under semiarid conditions. Agricultural Water Management, 50(3), 173-183. http://dx.doi.org/10.1016/S0378-3774(01)00105-6.

Li, X., Takahashi, T., Suzuki, N., \& Kaiser, H. M. (2011). The impact of climate change on maize yields in the

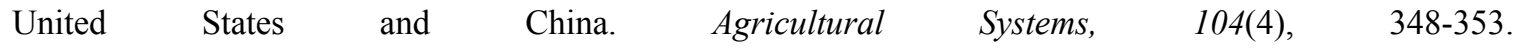
http://dx.doi.org/10.1016/j.agsy.2010.12.006.

Liu, C. A., Jin, S. L., Zhou, L. M., Jia, Y., Li, F. M., Xiong, Y. C., et al. (2009). Effects of plastic film mulch and tillage on maize productivity and soil parameters. European Journal of Agronomy, 31(4), 241-249. http://dx.doi.org/10.1016/j.eja.2009.08.004.

Liu, G., Yang, Q., Li, L., Fan, Y., Zhao, X., \& Zhu, Y. (2008). Study on soil water effects of the techniques of whole plastic-film mulching on double ridges and planting in catchment furrows of dryland corn. Agricultural Research in the Arid Areas, 6, 18-28. (in Chinese).

Liu, H. B., Lv, J. Z., \& Wang, M. S. (1989). The effect of horsebean sowed in the ridge with plastic film on the economic benefit. Gansu Agricultural Science and Technology, 3, 3-6 (in Chinese).

Luo, Y. (1982). Talking about the plastic film mulching. China State Farms, 3(3), 19-20 (in Chinese).

Ma, J., Ma, B., \& Chen, S. (2011). Effects of full mulch and double ridge-furrow techniques on maize in dryland. Ningxia Journal of Agriculture and Forestry Science and Technology, 2, 16-18 (in Chinese).

Ngigi, S. N. (2003). What is the limit of up-scaling rainwater harvesting in a river basin? Physics and Chemistry of the Earth, Parts A/B/C, 28(20-27), 943-956. http://dx.doi.org/10.1016/j.pce.2003.08.015.

Prinz, D. (1996). Water Harvesting: Past and Future. Balkema, Rotterdam: Proceedings, NATO Advanced Research Workshop, Vimeiro.

Reshmidevi, T. V., Eldho, T. I., \& Jana, R. (2009). A GIS-integrated fuzzy rule-based inference system for land suitability evaluation in agricultural watersheds. Agricultural Systems, 101(1-2), 101-109. http://dx.doi.org/10.1016/j.agsy.2009.04.001.

Shi, F., Wu, J., \& Yang, Y. (2008). The Research on the Application of Field Precipitation Collecting Measures in Dry Farming. Journal of Henan Agricultural Sciences, 9, 61- 64. (in Chinese).

Tian, Y., Su, D., Li, F., \& Li, X. (2003). Effect of rainwater harvesting with ridge and furrow on yield of potato in semiarid areas. Field Crops Research, 84(3), 385-391. http://dx.doi.org/10.1016/S0378-4290(03)00118-7.

Turner, N. C., Molyneux, N., Yang, S., Xiong, Y. C., \& Siddique, K. H. M. (2011). Climate change in south-west Australia and north-west China: challenges and opportunities for crop production. Crop and Pasture 
Science, 62(6), 445-456. http://dx.doi.org/10.1071/CP10372.

Wang, C. (2009). Double ridges and furrows plastic film mulch technology contributed $20 \%$ grain yield in Gansu province. Gansu Daily, January 17, 2009. (in Chinese).

Wang, L., Shao, M., \& Zhang, Q. (2004). Distribution and characters of soil dry layer in north Shaanxi Loess Plateau. Chinese Journal of Applied Ecology, 3, 436-442 (in Chinese).

Wang, T. C., Wei, L., Wang, H. Z., Ma, S. C., \& Ma, B. L. (2011a). Responses of rainwater conservation, precipitation-use efficiency and grain yield of summer maize to a furrow-planting and straw-mulching system in northern China. Field Crops Research, 124(2), 223-230. http://dx.doi.org/10.1016/j.fcr.2011.06.014.

Wang, X. L., Li, F. M., Jia, Y., \& Shi, W. Q. (2005). Increasing potato yields with additional water and increased soil temperature. Agricultural Water Management, $78(3), \quad$ 181-194. http://dx.doi.org/10.1016/j.agwat.2005.02.006.

Wang, X. (2010). Effects of full plastic film mulch and double ridge-furrows on maize in Linyou. Retrieved from http://www.sxny.gov.cn/Html/2010_04_29/41124_213637_2010_04_29_214042.html.

Wang, X., Zhang, X., \& Song, S. (2011b). Effects of mulching methods on soil water dynamics and corn yield of rain-fed cropland in the semiarid area of China. Chinese Journal of Plant Ecology, 8, 825-833 http://dx.doi.org/10.3724/SP.J.1258.2011.00825 (in Chinese).

Yan, C., Mei, X., He, W., \& Zheng, S. (2006). Present situation of residue pollution of mulching plastic film and controlling measures. Transactions of the Chinese Society of Agricultural Engineering, 22(11), 269-272 (in Chinese).

Yan, G., Yang, X., Wang, B., Xue, H., \& Li, X. (2010). Effect of Plastic Film-mulching on the Yield of Maize and Soil Condition. Journal of Anhui Agricultural Sciences, 38(12), 6405-6406, 6413 (in Chinese).

Ye, J. S., Li, F. M., Sun, G. J., Chen, Y. X., \& Mou, Y. L. (2010). A Multi- criteria Evaluation Approach to Access Agricultural Land Use Potential on the Loess Plateau of china. Intelligent Automation and Soft Computing, 16(6), 891-901.

Zhang, G., Jin, S., \& Zhang, L. (2005). Effects of different mulch techniques on maize in dryland of the north of Yuzhong. Gansu Agricultural Science and Technology, 9, 19-21 (in Chinese).

Zhang, K., \& Liu, B. (2010). Water erosion in the drylands of China. In L. Ci \& X. Yang (Eds.), Desertification and its control in China (pp. 217-261 (In Chinese)). Beijing: Higher Education Press, Springer.

Zhang, L., Niu, F., Li, X., Dou, G., \& Li, D. (2010). Effects of Planting in Furrow and Whole Plastic-film Mulching on Double Ridges in Autumn on Yield Index of Corn Production and Water Use Efficiency in Dry Lands. Chinese Agricultural Science Bulletin, 22, 142-145. (in Chinese).

Zhang, S., Li, P., Yang, X., Wang, Z., \& Chen, X. (2011). Effects of tillage and plastic mulch on soil water, growth and yield of spring-sown maize. Soil and Tillage Research, 112(1), 92-97. http://dx.doi.org/10.1016/j.still.2010.11.006.

Zhao, F. (2005). Advantage and application perspective of plasitic film mulch and double ridges rainwater harvesting techniques for maize. Tillage and Cultivation, 6, 62-63 (in Chinese).

Zhao, S. (1996). Introduction to Catchment Agriculture. Xi'an: Shaanxi Scientific and Technology Publishing House.

Zhen, Y. (2008). Effects of different mulch methods on maize in dryland. Serves of Agricultural Technology, 25(12), 18. (in Chinese).

Zhi, J. Q., Hu, F. S., Wu, H. L., Ma, S. W., Jia, Z. S., \& Zheng, Y. (2011). Yield Increasing Effect of Whole Film Mulching Mode for Dry Land Maize. Journal of Shanxi Agricultural Sciences, 6, 543-545. http://dx.doi.org/10.3969/j.issn.1002-2481.2011.06.16.

Zhou, L. M., Jin, S. L., Liu, C. A., Xiong, Y. C., Si, J. T., Li, X. G., et al. (2012). Ridge-furrow and plastic-mulching tillage enhances maize-soil interactions: Opportunities and challenges in a semiarid agroecosystem. Field Crops Research, 126(0), 181-188. http://dx.doi.org/10.1016/j.fcr.2011.10.010.

Zhou, L. M., Li, F. M., Jin, S. L., \& Song, Y. (2009). How two ridges and the furrow mulched with plastic film affect soil water, soil temperature and yield of maize on the semiarid Loess Plateau of China. Field Crops Research, 113(1), 41-47. http://dx.doi.org/10.1016/j.fcr.2009.04.005. 